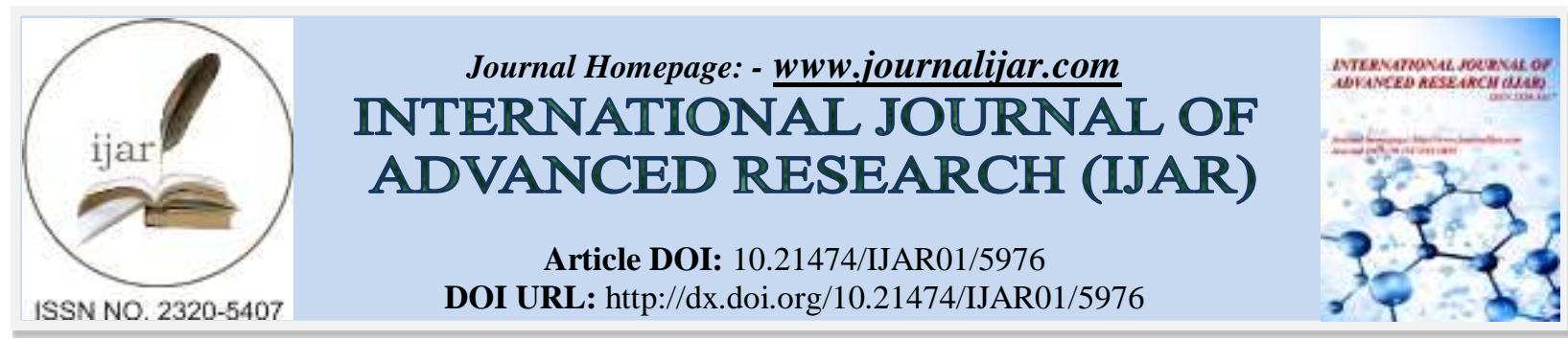

RESEARCH ARTICLE

\title{
PARTURIENTS WITH SEVERE PREECLAMPSIA EXPERIENCE LESS HYPOTENTION DURING SPINAL ANAESTHESIA FOR ELECTIVE CESAREAN DELIVERY THAN NORMOTENSIVE PARTURIENTS - A PROSPECTIVE RANDOMIZED CONTROL TRIAL.
}

Dr. Karuna Taksande ${ }^{1}$ and Dr. Pallavi Deulkar ${ }^{2}$.

1. Associate professor, Department of Anesthesia, Datta Meghe Institute of Medical Science, Sawangi (Meghe), Wardha.

2. PG student, Department of Anesthesia, Datta Meghe Institute of Medical Science, Sawangi (Meghe), Wardha.

\section{Manuscript Info}

(..........................

Manuscript History

Received: 05 October 2017

Final Accepted: 07 November 2017

Published: December 2017

\section{Key words:-}

severe preeclampsia, elective cesarean delivery, spinal anaesthesia, less hypotention.

\section{Abstract}

Introduction: Spinal anaesthesia is a form of regional anaesthesia which involves injection of local anaesthetic into subarachnoid space. Many severely preeclamptic parturients require cesarean delivery where spinal anaesthesia can be given.

Methods: Aim of study was to compare and evaluate onset and duration of sensory and motor block and heamodynamic effect of inj .bupivacaine $0.5 \%$ ( heavy) in severe preeclampsia parturients posted for cesarean delivery than healthy parturients.

Material and method: After approval from ethical committee ,100 patients were selected in age group of 20-30 with weight between 60 $90 \mathrm{~kg}$ undergoing cesarean delivery.

Results: Parturients with severe preeclampsia experienced less hypotention and more stable heamodynamics, during spinal anaesthesia who were posted for elective cesarean delivery than normotensive parturients.

Conclusion: Parturients with severe preeclampsia who are posted for elective cesarean delivery can be given spinal anaesthesia which will cause less hypotension and more stable heamodynamics.

Copy Right, IJAR, 2017,. All rights reserved.

\section{Introduction:-}

Spinal anaesthesia also called subarachnoid block is a form of regional anaesthesia which involves injection of local anaesthetic into subarachnoid space generally with a fine needle usually $9 \mathrm{cms}$ long. Regardless of anesthetic agent used ,the desired effect is to block the transmission of afferent nerve signals from peripheral nociceptors. Sensory signals from the site are blocked there by eliminating pain. The degree of neuronal blockade depends on the amount and concentration of local anesthetic used and the properties of the axon. Sedation is sometimes given to help patients to relax. Many severly preeclamptic parturients require cesarean delivery where spinal anaesthesia can be given. Because of hazards related to management of difficult airway and to the heamodynamic consequences of laryngoscopy and tracheal intubation general anaesthesia is only chosen when regional anaesthesia are contraindicated. Although spinal anaesthesia may be avoided in these parturients because of the risk of severe hypotension. This study was carried out in an effort to compare the hemodynamic changes in parturients with severe preeclampsia and healthy parturients undergoing spinal anesthesia for cesarean section. 
Our hypothesis is that severely preeclamptic parteurients submitted to spinal anesthesia for cesarean sections have the same degree of hypotension that of healthy parturients.

Aims and Objectives: To compare and evaluate the onset and duration of sensory and motor blockade and the heamodynamic effect of inj bupivacaine $0.5 \%$ heavy in severe preeclampsia parturients posted for ceasarean delivery than heathy parturients.

\section{Materials and Methods:-}

After approval from ethical committee, 100 parturients were selected in age group of 20-30 years with weight between $60-90 \mathrm{~kg}$ undergoing cesarean delivery.

The severely preeclamptic group (PE) was comprised by patients with systolic arterial blood pressure (SBP) $\geq 160$ $\mathrm{mmHg}$ or diastolic arterial blood pressure (DBP) $\geq 110 \mathrm{mmHg}$ and proteinuria $\geq 100 \mathrm{mg} / \mathrm{dL}$. [1]

To be considered eligible parturients had to meet all of the following inclusion criteria: single pregnancy, semielective or elective cesarean section, absence of labor (because labor can decrease the incidence of hypotension related to neuraxial anesthesia, absence of any coexisting or co-morbid conditions such as diabetes or renal impairment, no contraindication to neuraxial anesthesia and negative history of allergies to local anesthetics. The following healthy parturient (HP group) scheduled for elective cesarean section was selected after each PE was enrolled. Exclusion criteria for the HP group were: parturients with coagulopathy, abruptio placentae, placenta previa, HELLP syndrome, pulmonary oedema, cord prolapse, severe fetal distress, previous hypertension, cardiac disease, renal disease and thrombocytopenia ( $<100.000$ platelets $/ \mathrm{mm} 3)$. The PE group received a $4 \mathrm{~g}$ loading dose of intravenous magnesium sulfate (MgSO4) followed by $1 \mathrm{~g} / \mathrm{h}$ for $24 \mathrm{hrs}$ for seizure prophylaxis.. The interval between the administration of the last dose of magnesium sulfate and the start of cesarean section was at least 60 minutes.

Preoperative fluid administration, which was limited to $500 \mathrm{~mL}$ of Ringer's lactate solution I.V, was given upon arrival in the operating room, over 20 minutes. The patients were monitored with standard devices including automated blood pressure cuff, electrocardiogram, and pulse oximetry. Spinal anesthesia was performed in left lateral position, with 25-gauge Quincke's needle, via midline approach between L2-L3 or L3-L4 space. After observing the free flow of cerebrospinal fluid, $0.5 \%$ hyperbaric bupivacaine $2 \mathrm{ml}(10 \mathrm{mg})$ was injected into the subarachnoid space. The parteuriants were then put in a supine position with left uterine displacement with a wedge under the right flank. After the injection of the spinal drug, all parturients received IV Ringer's lactate solution at $100 \mathrm{~mL} / \mathrm{hr}$. Blood pressure assessment was started before performing the spinal anesthesia and was carried out every 10 minutes. Hypotension was defined as a $30 \%$ or greater decrease from baseline systolic blood pressure, and was treated with ephedrine $5 \mathrm{mg}$ IV bolus every 2 minutes until blood pressure was restored. Ephedrine use and total dose were recorded for each patient. Newborn APGAR scores were assigned by neonatologists not participating in the study.

\section{Results:-}

Parturients with severe preeclampsia experienced less hypotention and more stable heamodynamics, during spinal anaesthesia who were posted for elective cesarean delivery than normotensive parturients.

Overall, 100 parturients were included in the study, 50 in the PE and 50 HP group. Demographic maternal and neonatal characteristics are depicted in Table 1. Parturients in the $\mathrm{PE}$ group had higher mean body weight $(\mathrm{P}=0.04)$, lower gestational age $(\mathrm{P}=0.003)$ and their newborns had lower birth weights $(\mathrm{P}=0.006$; Table 1$)$. Table 2 presents the data on hemodynamic parameters and vasopressor use. There was no statistically significant difference between the 2 groups regarding the occurrence of hypotension, ephedrine use or total ephedrine dose. The mean drop in systolic blood pressure was $27.5 \%$ in the PE group and 24, $2 \%$ in the HP group $(\mathrm{P}=0.21)$. Diastolic blood pressure decreased by $33.1 \%$ and $35.9 \%$ in the PE and HP groups, respectively $(\mathrm{P}=0.31$; Table 2$)$. 
Table 1:- Demographic Maternal and Neonatal Characteristics.

\begin{tabular}{|l|c|c|c|}
\hline & Severe Preeclampsia & Healthy Parturients & $P$ \\
\hline Age (years) & $24.8 \pm 5.8$ & $25.2 \pm 6.2$ & $0.83 \#$ \\
\hline Body weight $(\mathrm{kg})$ & $79.1 \pm 15.7$ & $69.4 \pm 12.3$ & $0.04 \#$ \\
\hline Height $(\mathrm{cm})$ & $160.2 \pm 5.6$ & $157.1 \pm 7.5$ & $0.15 \#$ \\
\hline Number of pregnancies & $2.26 \pm 1.59$ & $2.95 \pm 1.95$ & $0.23 \#$ \\
\hline Gestational age (weeks) & $35.9 \pm 2.9$ & $38.6 \pm 2,3$ & $0.003 \#$ \\
\hline Newborn birth weight (g) & $2596 \pm 733$ & $3182 \pm 511$ & $0.006 \#$ \\
\hline 1-minute APGAR & $7.79 \pm 1.13$ & $8.25 \pm 1.0$ & 0.20 * \\
\hline 5-minute APGAR & $8.79 \pm 0.85$ & $9.20 \pm 0.76$ & 0.12 * \\
\hline
\end{tabular}

\# Data are mean $\pm \mathrm{SD},{ }^{*}$ median (range). Unpaired Student's t-test; Mann-Whitney U-test; Chi-square test, Fisher's exact test.

Table 2:- Hemodynamic Parameters and Vasopressor Use.

\begin{tabular}{|l|c|c|c|}
\hline $\begin{array}{l}\text { Baseline SBP } \\
(\mathrm{mmHg})\end{array}$ & $158.2 \pm 19.9$ & $141.1 \pm 18.9$ & $0.009 \#$ \\
\hline $\begin{array}{l}\text { Lowest SBP }(\mathrm{mmHg}) \\
\text { SBP decrease }(\%)\end{array}$ & $114.1 \pm 18.4$ & $107.6 \pm 16.7$ & $0.25 \#$ \\
\hline $\begin{array}{l}\text { Baseline DBP } \\
\text { (mmHg) }\end{array}$ & $-27.6 \pm 10.3$ & $-24.2 \pm 12.4$ & $0.21 \#$ \\
\hline $\begin{array}{l}\text { Lowest DBP }(\mathrm{mmHg}) \\
\text { Mean total ephedrine } \\
\text { dose }(\mathrm{mg})\end{array}$ & $62.2 \pm 11.9$ & $85.5 \pm 12.4$ & $0.09 \#$ \\
\hline Hypotension, $\mathrm{n}(\%)$ & $11.0 \pm 11.4$ & $54.2 \pm 10.1$ & $0.047 \#$ \\
\hline
\end{tabular}

Data are mean $\pm \mathrm{SD},{ }^{*} \mathrm{n}(\%)$. Unpaired Student's t-test; Mann-Whitney U-test; Chi-square test, Fisher's exact test. SBP = systolic blood pressure; DBP = diastolic blood pressure. 


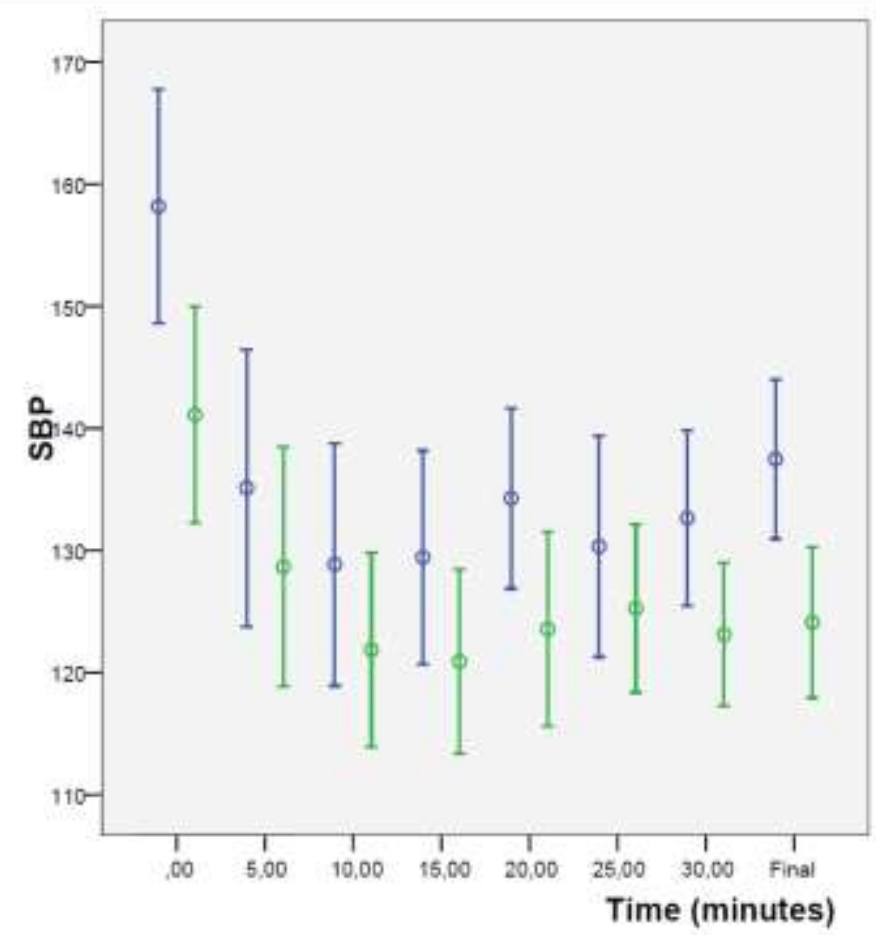

I PE

I $\mathrm{HP}$

Figure 1: Systolic blood pressure variations. Mean ( $95 \% \mathrm{Cl})$. SBP - Systolic blood pressure. $\mathrm{PE}=$ severe preeclampsia; $\mathrm{HP}=$ healthy parturients.

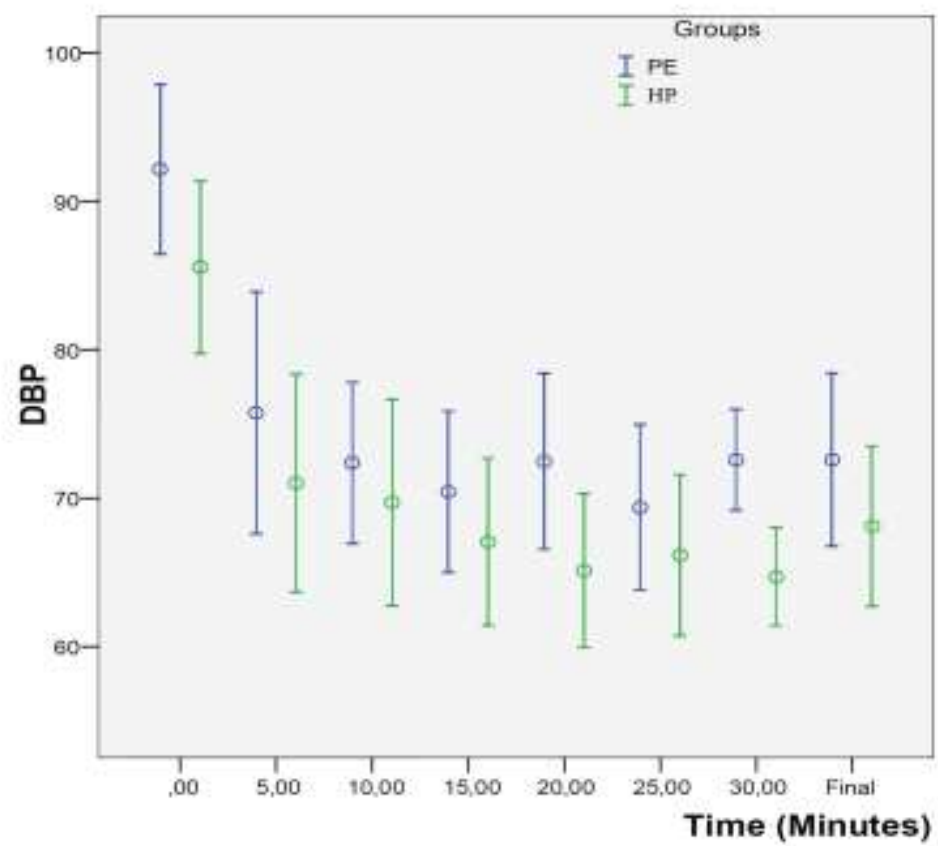

Figure 2: Diastolic blood pressure variations. Mean ( $95 \% \mathrm{CI})$. DBP - Diastolic blood pressure. $\mathrm{PE}=$ severe preeclampsia; $\mathrm{HP}=$ healthy parturients. 
Mean SBP was significantly higher in the PE group at baseline, 20 minutes, 30 minutes, and at the end of the procedure (Figure 1). The PE group also exhibited higher mean DBP at baseline, 30 minutes, and at the end of cesarean section.

\section{Discussion:-}

The evaluation of the hemodynamic response of patients with severe preeclampsia who were given spinal anesthesia for cesarean section to that of healthy parturients, was done in this study. No significant difference was found between the two groups regarding the occurrence of hypotension, decrease of blood pressure, vasopressor use, mean total vasopressor dose or newborn well-being. Severely preeclamptic patients showed significantly higher systolic and diastolic blood pressures before, throughout and at the end of cesarean section.

During the comparision of the hemodynamic effects of spinal anesthesia in severely preeclamptic and term healthy parturients, Aya et al. [2] found that the incidence of hypotension was 6 times less in severely preeclamptic patients. However, in their study they did not standardized the treatment for hypertension, fluid administration and anesthetic dose used, which can alter the hemodynamic response related to the neuraxial blockade, making improper interpretation of the data.

After all the methodological shortcomings two hypotheses were given by Aya et al. firstly, preeclampsia associated factors could be implicated. Secondly, provided that the healthy parturients in such study had more advanced gestational age and their newborn's body weight was significantly higher, the possibility that a lesser degree of aortocaval compression had been responsible for the smaller frequency of hypotension in the severe preeclampsia group was also considered [3].

In order to determine whether severe preeclampsia affected the hemodynamic response to spinal anesthesia the same group compared severe preeclamptics to preterm women with comparable newborn weight who were also being given spinal anesthesia for cesarean section [4]. Hypotension was half in preeclamptic patients, which suggests the existence of preeclampsia-associated factors. Whereas, preeclamptic patients required less ephedrine than women in the preterm group to restore blood pressure to baseline levels, the decrease in systolic, diastolic, and mean arterial blood pressure was same between groups.

Adding further evidence to the safety of spinal anesthesia, Dyer et al., using lithium dilution cardiac output monitoring in severely preeclamptic patients, told that neither spinal anesthesia nor treatment of hypotension with modest doses of phenylephrine reduces maternal cardiac output during caesarean section, further supporting the safety of neuraxial blockade in this patient population [5].

About fetal well-being, it had been said that the sympathectomy attributable to spinal anesthesia could reduce uteroplacental blood flow in preeclamptics, leading to worse neonatal outcomes. Conversely, several studies supporting the safety of spinal anesthesia in these patients have been published, and neuraxial anesthesia for labor pain relief has even been shown to increase placental blood flow in patients with severe preeclampsia [6].

\section{Conclusion:-}

The hemodynamic changes and newborn wellbeing appeared to be comparable in severely preeclamptic and healthy parturients who were given spinal anesthesia for cesarean section.

Parturients with severe preeclampsia who are posted for elective cesarean delivery can be given spinal anaesthesia which will cause less hypotension and more stable heamodynamic.

Spinal anesthesia seems to be a safe option for parturients with severe preeclampsia undergoing cesarean section. 


\section{References:-}

1. Hemodynamic Effects of Spinal Anesthesia for Cesarean Section are Equivalent in Severely Preeclamptic and Healthy Parturients. Florentino Fernandes Mendes*, Gustavo Hennemann, Ana Luft, Carlos Farias and Sheila Braga.

2. Aya AG, Mangin R, Vialles N, Ferrer JM, Robert C, et al. (2003) Patients with severe preeclampsia experience less hypotension during spinal anesthesia for elective cesarean delivery than healthy parturients: A prospective cohort comparison. Anesth Analg 97: 867-872.

3. Santos AC, Birnbach DJ (2003) Spinal anesthesia in the parturient with severe preeclampsia: time for reconsideration. Anesth Analg 97: 621-623

4. Aya AG, Vialles N, Tanoubi I, Mangin R, Ferrer JM, et al. (2005) Spinal anesthesia-induced hypotension: A risk comparison between patients with severe preeclampsia and healthy women undergoing preterm cesarean delivery. Anesth Analg 101: 869-875.

5. Dyer RA, Piercy JL, Reed AR, Lombard CJ, Schoeman LK, et al. (2008) Hemodynamic changes associated with spinal anesthesia for cesarean delivery in severe preeclampsia. Anesthesiology 108: 802-811.

6. Jouppila P, Jouppila R, Hollmen A, Koivula A (1982) Lumbar epidural analgesia to improve intervillous blood flow during labor in severe preeclampsia. Obstet Gynecol 59: 158-161. 